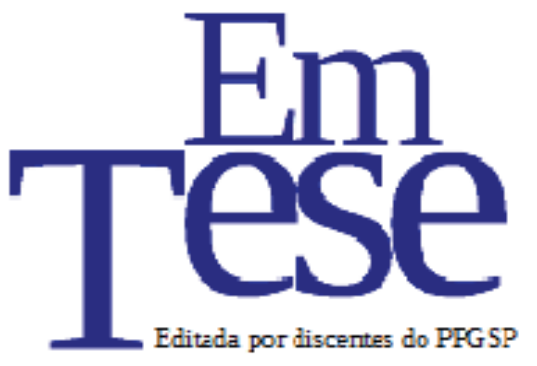

UFSC

PPG SP PROG RAMA DE

PÓS-GRADUAÇÃO EM

Sociologia

Política

\title{
A produção de uma disciplina escolar: um estudo sobre as concepções de ensino e as estratégias metodológicas empregadas por professores(as) de Sociologia
}

\section{Eduardo Carvalho Ferreira ${ }^{1}$}

Resumo: Em sua condição atual a disciplina escolar de Sociologia pode parecer mais estável e consensual do que alguns anos atrás, no entanto, ainda persistem muitas dúvidas sobre seu projeto disciplinar. Sua recente consolidação como disciplina escolar tem produzido uma história curricular bastante oscilante em virtude das inovações educativas trazidas pelas políticas educacionais do período pós Lei 3.934/96. Fruto desse contexto emergem concepções de ensino e estratégias metodológicas para fomentar a produção da disciplina. Neste artigo apresento algumas ideias a partir de uma pesquisa sobre o que pensam os professores de Sociologia e os efeitos de suas representações nas práticas de ensino.

Palavras-chave: Sociologia. Disciplina. Escola. Ensino.

\section{The production of a school subject: a study about teaching concepts and methodological strategies employed by Sociology teachers}

\begin{abstract}
In your current condition the school discipline of Sociology may seem more stable and consensual than a few years ago, however, there are still many questions about your disciplinary project. His recent consolidation as school discipline has produced a rather mixed history curriculum because of the educational innovations brought by the educational policies of the period after the Law 3.934/96. Fruit this context emerge teaching concepts and methodological strategies to promote the production of subject. In this article I will present some ideas from research on what they think the Sociology teachers and the effects of their representations in teaching practices.
\end{abstract}

Keywords: Sociology. Subject.School.Teaching.

\footnotetext{
${ }^{1}$ Possui mestrado em Ciências Sociais pela Universidade Estadual de Londrina (UEL) e atualmente é doutorando em Educação pela Universidade de São Paulo (USP). E-mail: edu.ferreira@usp.br.
} 


\section{Introdução}

Após a sua reintrodução nas discussões curriculares dos anos 1990, a disciplina escolar de Sociologia na educação básica tem respondido uma série de interrogações sobre sua necessidade e segue em busca de legitimidade frente ao discurso de modernização da escola. Apesar de contestado, pode-se dizer que o processo recente de institucionalização da disciplina tem sido bem sucedido, se consideramos que fora uma tentativa de se inserir um conteúdo relativamente novo no contexto do quadro geral do currículo oficial. Entretanto, este não tem sido um processo simples, já que seu ensino sempre fora bastante questionado e muitas reflexões e opiniões o tratam de maneira sumaria e caricatural, demonstrando até certo ponto desconhecimento sobre sua história, realidade e atividade.

Assim, no afã de contribuir para um melhor entendimento sobre a disciplina escolar de Sociologia, neste artigo analisarei algumas entrevistas feitas com professores da educação básica, com a intenção de problematizar a noção de conhecimento escolar produzida pelos mesmos em suas práticas pedagógicas. Tal inventário nos coloca em posição de refletir sobre as suas questões mais internas, no que diz respeito às condições processuais da construção da própria disciplina, o tratamento metodológico, a organização dos conteúdos, as representações sobre ciência e conhecimento escolar. A partir dessas representações dos professores talvez possamos compreender melhor como o conhecimento escolar de Sociologia tem sido produzido.

Os dados analisados foram extraídos de uma pesquisa realizada no ano de 2011, com uma base de dez professores de Sociologia no Ensino Médio da rede pública estadual do município de Londrina-PR. Optou-se pela realização de entrevistas semiestruturadas, realizadas individualmente. O objetivo das entrevistas foi perceber a partir das descrições das experiências em torno do ensino escolar de Sociologia as representações dos professores sobre o conteúdo do ensino, as suas finalidades, seus métodos e metodologias, a relação entre as propostas curriculares e as práticas de ensino, em suma, seus entendimentos sobre o conhecimento escolar de Sociologia, as aproximações e os distanciamentos.

A seleção dos professores entrevistados atendeu dois critérios essenciais: 1) ter formação em Ciências Sociais; 2) pertencer a instituições públicas de ensino. Cabe 
ressaltar que esta é uma pesquisa de abordagem qualitativa que não teve como preocupação o rigor estatístico, por isso a definição do número de professores que compõem a amostragem não corresponde a um número proporcional ao total de professores locados nas escolas da cidade de Londrina. Para manter íntegra a identidade dos entrevistados, no corpo do texto suas falas serão representadas pelas letras $A, B, C$, $D, E, F, G, H, I$ e $J$, cada uma correspondendo a um sujeito da pesquisa.

As disciplinas são parte de um discurso dominante sobre determinado conhecimento e sua existência esta cercada de parâmetros para suas práticas. Nesse sentido, as definições preliminares empregadas pelos professores são cruciais para entender como a Sociologia esta engajada com a escolarização. Suas falas poderão ser elucidativas pelo fato de que carregam em sua história social aspectos multifacetados, definidos e negociados em um espaço social diversificado e em relação a um número variado de agentes. São variadas as possibilidades sociológicas de um estudo sobre as disciplinas que valorize as relações entre os pontos de vista discursivos dos professores e a história social dos currículos. Este é um tipo de trabalho sociológico que parece essencial para a compreensão do conhecimento escolar. É o que podemos nomear como o desenvolvimento de "uma perspectiva social construtivista para o estudo das disciplinas escolares" (GOODSON, 1995, p. 65-80).

\section{Alguns apontamentos preliminares}

Não é simples falar sobre os dilemas que envolvem a inserção de uma disciplina na organização curricular como um todo. Muito menos quando se trata de situar um diagnóstico das suas perspectivas e dos seus obstáculos. Inserir um conteúdo no sistema de ensino não é tarefa das mais fáceis de realizar, seja no Brasil ou em outro país. Para compreender tal complexidade basta resgatarmos a história de algumas das principais reformas educacionais contemporâneas e seus intrincados mecanismos de legitimação curricular. Sabe-se, já há algum tempo, que a demanda pelas disciplinas escolares responde as influências do contexto global da sociedade e as suas necessidades de formação especificas. É como disse Michael Young em Knowledge and Control (1971), “currículos são, sim, invenções sociais”, já que eles não poderiam ser entidades 
abstratas, rígidas e fechadas, pois seu desenvolvimento, evolução e transformação estão submetidos ao jogo competitivo travado na relação entre educação e sociedade.

Historicamente, tem sido por intermédio das disciplinas que o conhecimento é transmitido nas escolas. A rigor, as disciplinas escolares devem ser vistas como campos de poder inseridos em um espaço de produção repleto de disputas em torno de interesses, ações e significados. Ivor Goodson escreveu no livro O currículo em mudança (1997), "que as disciplinas escolares são práticas institucionalizadas que proporcionam uma estrutura para a ação escolar", referindo-se ao entendimento de que as mesmas são produtos de escolhas que antecedem os fatores estritamente epistemológicos e que a sua inserção nos currículos depende das condições sociais, políticas, econômicas, mas, sobretudo, científicas e acadêmicas.

O próprio de uma reflexão sociológica ou histórica sobre os saberes escolares é contribuir para dissolver esta percepção natural das coisas, ao mostrar como os conteúdos e os modos de programação didática dos saberes escolares se inscrevem, de um lado, na configuração de um campo escolar caracterizado pela existência de imperativos funcionais específicos (conflitos de interesses corporativos, disputas de fronteiras entre as disciplinas, lutas pela conquista da autonomia ou da hegemonia no que concerne ao controle do currículo), de outro lado na configuração de um campo social caracterizado pela coexistência de grupos sociais com interesses divergentes e com postulações ideológicas e culturais heterogêneas, para os quais a escolarização constitui um trunfo social, político e simbólico (FORQUIN, 1992, p. 43-44).

Contudo, o desafio teórico é perceber isso ao analisar a evolução de uma disciplina em particular, já que cada uma assume um projeto a ser realizado, quer dizer, elas são pensadas e inseridas para fornecer, pelo menos teoricamente, soluções para problemas mais amplos. Isto é, a produção de uma disciplina escolar passa pela construção de um discurso social, político e acadêmico, pois a disciplina é "uma construção social que possui intersecções com os padrões de relações sociais e as suas estruturas, além de intimamente implicadas nos processos de reprodução e transmissão cultural" (GOODSON \& MARSH, 1996, p. 1). Compreender a organização e a produção de uma disciplina escolar requer prestar atenção não só no currículo escrito, mas também nos discursos e as verdades que justificam a sua excelência, já que "uma 
disciplina se define tanto por suas finalidades quanto por seus conteúdos" (JULIÁ, 2002, p. 45).

Cabe ressaltar, que os estudos sobre a produção das disciplinas escolares feitos a partir da chamada nova Sociologia da Educação é que começaram a dizer algo a mais sobre esse caráter histórico e político da constituição e transformação das mesmas, pois passaram a considerar, dentre outros detalhes, que "a disciplina (escolar) é um principio de controle da produção do discurso. Ela lhe fixa os limites pelo jogo de uma identidade que tem a forma de uma reatualização permanente das regras" (FOUCAULT, 1999, p. 36). Nesse sentido, é que se diz que a produção de uma disciplina escolar requer a criação de espaços de proposição, de consenso e de ajuste de perspectivas teóricas e metodológicas.

Por essa razão, diz-se na literatura especializada que as disciplinas são uma das criações mais originais das culturas escolares ${ }^{2}$, justamente, por essa dinâmica atribuída a sua existência. Seguindo esse raciocínio, é possível dizer que as mesmas são portadoras de uma materialidade histórica única e que, além disso, possuem a virtude notável de se transfigurarem. Para Antonio Vinão Frago (2007, p. 89), as disciplinas "transformam-se ou desaparecem, afastam-se e unem-se, repelem-se e absorvem-se. Mudam as suas denominações, modificam seus conteúdos. Vistas deste modo são organismos vivos". Mas, sobretudo, são também espaços de poder, de um poder em concorrência, sendo precisamente essa concorrência que faz misturar nesses espaços uma série de interesses e agentes.

Dentre outras sentenças, uma disciplina escolar pode ser entendida como produto da determinação de um grupo e/ou comunidade que se apresenta ante ela mesma como especialista em seus domínios. Sua configuração passa necessariamente pelo crivo daqueles que a ela se dedicam, o que denota saber sobre a formação e as representações dos mesmos e as implicações que isto teve sobre a produção da disciplina. Neste caso não pode haver desagregação entre tais aspectos, pois isso poderia acarretar em uma compreensão incompleta desse contexto de produção. A exploração da lógica dos elementos envolvidos no processo e de suas frentes de atuação corresponde a uma

\footnotetext{
${ }^{2}$ Entendidas como um conjunto de práticas e procedimentos historicamente constituídos sob a forma de um arquétipo no interior dos sistemas de ensino e das instituições escolares (Cf. CHERVEL \& COMPERE, 1999; JULIA, 2002; VINÃO FRAGO, 2007).
} 
tentativa de sintaxe da dimensão micropolítica da disciplina, lugar onde se articulam os interesses da própria comunidade disciplinar implicada.

Especificamente, sobre a disciplina escolar de Sociologia, pode-se afirmar que com a conquista da sua obrigatoriedade em 2008 tivemos uma virada que resultou em um contexto de grande aproximação de pessoas e grupos interessados na sua produção. Com o passar do tempo esse envolvimento tem se materializado em eventos, produções e representações que contribuem cada vez mais para estabilizar determinados sentidos e que corrobora com o seu processo de legitimação nos campos Educacional e das Ciências Sociais.

A história recente da Sociologia no Ensino Médio $^{3}$ é caracterizada pela integração de uma comunidade disciplinar que passa a ser interlocutora dos assuntos relativos à produção do ensino e seus objetos, tarefa que tem reforçado sua ratificação curricular. Isto é, na medida em que essa comunidade disciplinar consegue estabelecer parâmetros de atuação na política e no campo acadêmico, se constitui ela própria como sujeito da institucionalização da disciplina. O projeto político pedagógico da disciplina vai refletindo cada vez mais a conveniência das disposições subjetivas desta comunidade na sua busca por legitimação. De fato, é um contexto sui generis, que se configura a partir da coalizão de agentes e instituições promotoras de ações para a produção da disciplina.

\section{Currículo, conhecimento, ensino e aprendizagem}

Elencar os elementos que envolvem uma teoria sobre a construção do conhecimento escolar representa considerar os papeis distintos que são atribuídos a aquilo que se quer conhecer, ou seja, os objetos do ensino. E compreender esse processo significa esclarecer quais concepções de sujeito e de objeto empregadas e que norteiam as premissas da própria disciplina. É sabido que o sistema de ensino escolar é um contexto que possui linguagens e valores próprios, que são bastante diferentes daqueles compartilhados pela academia e cujos pressupostos têm implicações diretas na construção do conhecimento. Assim, o conteúdo do ensino escolar de Sociologia está concentrado em aspectos que procuram atender a essa premissa pedagógica, o que representa na prática construir uma proposta de ensino que opere no sentido de

\footnotetext{
${ }^{3}$ Cf. NEUHOLD, 2014.
} 
fortalecer os vínculos entre a ciência de referência e o currículo oficial prescrito para o Ensino Médio.

[...] o quê entra em conflito em alguns momentos é ele ter o conhecimento sociológico; ou seja, conhecer e saber o que é a cultura, saber o que é trabalho, saber o que é Estado, saber o que é socialização, ou ele conseguir desenvolver o conhecimento reflexivo. $(F)$

[...] Entendeu? A impressão que eu tenho é que: é para ter o conhecimento da graduação, tipo ter uma base do que é a graduação em ciências sociais, do que faz um sociólogo? Do que pensa um sociólogo, um antropólogo ou um cientista político? Ou é para ele poder se relacionar com a sociedade "pós"escola? O que eu acho é o seguinte: que deveria se voltar mais para a formação dele "pós" escola, do que para o conhecimento que é adquirido na graduação. (E)

[...] E nesse meio tempo os alunos nos pedem muita coisa. Eles pedem, nem que seja assim: "Professora, vamos fazer um debate, nós estamos tendo problemas aqui na sala em relação a preconceitos, a discriminação? $(J)$

Formalmente, diferente de outras disciplinas escolares, o ensino escolar de Sociologia ainda não apresenta um conjunto estruturado de conteúdos para organizar seu currículo. Não há, de fato, um consenso sobre quais tópicos e perspectivas a serem ensinados ${ }^{4}$. Mesmo que atualmente já exista certa linearidade a esse respeito, pode-se entender que forma e conteúdo têm variado de acordo com as circunstâncias. Grosso modo, ao pensar na organização do ensino, os professores ainda demonstram uma convicção de que o conhecimento escolar de Sociologia disponibiliza aos estudantes novos caminhos para pensar sobre a realidade social e os dilemas próprios a cotidianidade.

A disposição dos conteúdos tem seguido uma lógica que visa atender a necessidade de não fragmentar os conhecimentos das Ciências Sociais, articulando todas as suas dimensões. A seleção costuma basear-se na articulação dos autores e conceitos fundamentais com as teorias e os temas, construindo certa hierarquia entre os saberes e estabelecendo um vínculo que permita dar conta, ao longo dos três anos do Ensino Médio, de proposta articulada entre aspectos científicos e temáticos.

\footnotetext{
${ }^{4}$ Vejam as polêmicas em torno do debate sobre a Base Nacional Curricular Comum.
} 
[...] Eu acho que o primeiro ano mesmo, tem que entrar é com uma noção dos clássicos, todos os conceitos, fato social, consciência coletiva, classes sociais, estamentos, só que sempre lembrando que você tem que trazer esses assuntos para realidade dos alunos. (B)

[...] no primeiro ano eu trabalho alguns conceitos básicos dos três autores, o Karl Marx, o Emile Durkheim e Max Weber. (A)

[...] meu objetivo a partir do segundo ano, principalmente, é que eles vejam o método a cada temática que eu for usar, pra eles perceberem que tudo é construído, que nada é natural. A questão da desnaturalização mesmo do mundo. $(F)$

[...] Aí você vai para o segundo ano, o objetivo é começar a introduzir questões como trabalho, cultura e sociedade, daí trazendo mais para a prática. $(G)$

[...] com o terceiro ano eu entro mesmo na questão dos temas como as desigualdades sociais, a política, a cidadania, os mecanismos ideológicos, justamente trabalhando as questões sociais. $(\mathrm{J})$

Um aspecto significativo a ser destacado é a proposição que é feita quanto ao currículo, o que envolve a estruturação das atividades e a seleção dos conteúdos, que se define simultaneamente num principio cuja orientação é a abordagem temática e conceitual, o que gera uma noção de conhecimento escolar de Sociologia concebida com base numa lógica de organização estruturada pelos conceitos científicos subordinados às temáticas significativas aos estudantes. Tem-se a expectativa de que seu ensino ajude a construir soluções a problemas. Isto é, a tarefa do ensino se coloca como um diálogo entre ciência e realidade.

Essa discussão sobre a forma e o conteúdo que a disciplina escolar de Sociologia deveria adotar tem acompanhado todo o seu processo de desenvolvimento. De fato, muitos dos aspectos apresentados pelos professores para a construção da disciplina estão relacionados com a pretensão de se fornecer um tipo de conhecimento especializado, que simultaneamente, não seja eminentemente acadêmico e que não abandone essa matriz. Esse conhecimento se traduz como uma conversão dos conhecimentos científicos conformados e acumulados nas fronteiras do saber escolar, quer dizer, essa conversão retrata um conhecimento que busca sua legitimidade na superação da simples transposição mecânica dos conhecimentos produzidos na universidade. 
[...] Então isso foi uma coisa que agente discutiu, que tipo de conhecimento deve ser trabalhado ali, aquele conhecimento que é produzido na universidade ou um conhecimento diferenciado. (C)

[...] Lá na universidade a gente trabalha a teoria e quando você vai trabalhar teoria aqui com o aluno do ensino médio tem perfis totalmente diferentes, conforme a maturidade do aluno você vai dar um enfoque e trabalhar de forma diferente. (E)

Há certo consenso que, mais do que discorrer sobre uma série de conceitos, a disciplina escolar de Sociologia precisa estar preocupada em contribuir com a formação humana na medida em que pode proporcionar a problematização da realidade próxima dos educandos. Tem-se a compreensão de que seus conhecimentos enquanto elementos para a promoção de uma sociedade mais esclarecida. E isso pode acontecer na medida em que se alia o conhecimento sociológico à vivência cotidiana dos estudantes. Desta forma, a aprendizagem é considerada nos termos de um empreendimento científico e prático que favoreça o enriquecimento pessoal através do exercício do método. Trata-se o conhecimento escolar como conhecimento científico em ação, ou seja, os conceitos e teorias sendo objetivados.

[...] (um aluno diz) eu não gosto de Sociologia e aí vinha a pergunta: Por que? Porque faz pensar, porque me faz ver o mundo de uma forma mais crítica, porque ela me fez acordar para realidade que eu vivo. E aí é isso que a gente quer mesmo, sabe. Esse é o papel da Sociologia. (I)

[...] Eles passam a ficar mais atentos ao que acontece na sociedade, tanto que muito deles que passaram por mim e estão dentro da universidade, é muito comum eles mandarem recadinhos: Olha vai ter eleição para reitor e vieram discutir com a gente aqui no nosso curso isso, olha professora estão discutindo a inclusão, eles mandam recado para dizer o quanto estão atentos ao que está acontecendo a volta deles. $(J)$

[...] Aprender Sociologia e Filosofia, quando se é adolescente é essencial para desconstrução de um mundo formado por estereótipos, por preconceitos, por discriminações, é a desmistificação da realidade. $(F)$

Os discursos dos professores demonstram a preocupação de evitar que a disciplina escolar se degenere numa simples valorização do senso comum sob a forma de um conhecimento especializado. Como sabemos isto é especialmente recorrente no caso da Sociologia no ensino médio. Há o reconhecimento de que a Sociologia é um tipo de 
conhecimento especializado e que suas questões não nos direcionam necessariamente ao entendimento espontâneo da realidade social. Assim, a finalidade do ensino não deve se restringir à mera aquisição formal dos conhecimentos, mas, sobretudo no desenvolvimento de algumas capacidades como a problematização e argumentação.

[...] serve para que ele se veja realmente como ser que atua ali dentro da sociedade e que sua ação não é individual, que a ação dessa pessoa está relacionada com a coletividade, as opções que ele acha que são pessoais, não são pessoais, que suas escolhas refletem a coletividade e isso que ele tem que perceber. (E)

Nesse sentido, os professores parecem tender a recusar certas aspirações teleológicas do conhecimento escolar de Sociologia. Apresentam uma perspectiva que vai ao sentido contrário daquelas que desejam moldar a disciplina e seu ensino com base num nomotetismo e na separação entre teoria e método. Assim, a maioria dos depoimentos aponta que o conhecimento escolar de Sociologia deve partir de situações reais que os estudantes conhecem e vivenciam e que exigem para interpretá-las a introdução dos conhecimentos contidos nas teorias científicas. A meta é problematizar essas situações propiciando um distanciamento crítico do estudante.

[...] a Sociologia não veio para salvar o mundo, mas, eu acho interessante enquanto ciência porque através dela nos podemos levar nossos alunos a refletir, eu acredito nisso, me lembro de um evento, no ano passado, quando uma aluna do segundo ano de uma escola, falou, depois de nós discutirmos o processo de trabalho - taylorismo, fordismo e toyotismo - Professor eu não posso ver carro da Toyota que eu me lembro da teoria, isso é ótimo. (A)

Mas o que se deseja em relação ao seu ensino? Aqui uma resposta multifacetada. Primeiro, o conhecimento escolar precisa corresponder às reais necessidades dos estudantes, tratar do que, de fato, é relevante. Segundo, ser crítico. Não se conformar com aquilo que é manifestação imediata, carece explicar o mundo da vida e a condição humana. Em terceiro lugar, precisa ser construído numa interação, onde possa ser transferido para outras situações e que possa ser uma ferramenta reflexiva. E por último, algo que se incorpora no sujeito como visão de mundo, que passa a fazer parte dele, porque é significativo. Com efeito, a premissa do ensino escolar de Sociologia é apresentada nesses termos e sua a importância consiste em desenvolver um tipo de 
conhecimento que represente a possibilidade de construção de sentido para os estudantes, quaisquer que sejam suas escolhas.

Esse argumento articula-se com a defesa de um conhecimento escolar em Sociologia que proporcione uma cultura científica escolar mediante a formulação de um ethos questionador e desconstrutivo típico de uma ciência que se propõe a investigar a condição humana. Por suposto, tal ensino além de prestar-se a sua matriz acadêmica, deve também organizar de modo próprio seus saberes a serem ensinados, suas regras, linguagens e objetivos. Isso se refere a um processo que não é instantâneo, mas que, no entanto, busca estimular a busca por explicações mais aprofundadas mediante os nexos fornecidos pela Sociologia.

E isso implica em um processo bastante complexo de transformação da ciência em conteúdo de ensino escolar. É complexo porque se refere a um processo que não pode ser simplificado, isto é, reduzido a partes tratadas independentemente umas das outras, e por isso exprime uma série de antagonismos marcados pela presença de diversos fatores e interesses corporativos.

[...] para que eles desnaturalizem, porque a partir desse momento ele passa a enxergar de outra forma, mesmo que for saber de uma forma primária, mas que ele tiver essa possibilidade de tentar olhar aquilo de uma forma diferente já fez diferença, e também acho que, eu tava discutindo com a professora lá hoje, a gente dá voz para eles, parece que é assim, a forma de ensino tradicional deixa o aluno numa situação passiva e eles estão sempre assim. Você chega na sala e eles tão sempre assim e quando você dá voz eles não gostam no começo: Vamos fazer um debate? Ah eu não gosto de fazer debate, não gosto de falar, então pelo fato de você ouvir e você dar voz para eles também é muito importante. $(C)$

[...] Mesmo que eles nunca tivessem tido contato, não interessa, eles têm condições, capacidade de compreender e desenvolver aqueles raciocínios. Agora, a estrutura da escola, as regras extremamente rígidas, aquela coisa de estar todo mundo tão acostumado com aquele cotidiano que não se pensa. (I)

Os professores colocam como objetivo principal a construção e o desenvolvimento de um olhar sociológico que permita ao estudante compreender e se situar na sociedade em que vive. O compromisso normativo da disciplina seria apresentar as questões levantadas pela Sociologia, possibilitando transformar os problemas particulares dos estudantes em questões sociais e engajando suas condutas. 
Podemos extrair desse debate que o ensino escolar de Sociologia é concebido por suas atribuições, existe assim uma preocupação dos professores em trabalhar com seus alunos certas questões metodológicas e isso é colocado como fundamental.

[...] Para mim o objetivo é desenvolver o raciocínio dos alunos, pela percepção, desnaturalização do mundo mesmo, percepção de que as coisas foram construídas, percepção de que eles têm atuação nessa construção. $(G)$

Assim, as especificidades da disciplina escolar de Sociologia são organizadas em três níveis: 1) a conceitualização dos objetos. Trata-se de confrontar o estudante com situações que exijam classificar, distinguir e explicar os objetos de conhecimento, elaborando conceitos a partir do equilíbrio no tratamento das teorias e autores; 2) a problematização das questões. Remonta em encontrar e relacionar as questões sociológicas com enunciados concretos, colocando sob suspeita as afirmações do senso comum e procurando respostas aos diferentes problemas sociais; e 3) a argumentação. Que o estudante manifeste sob a forma de ação e significado, por meio da linguagem, por exemplo, capacidade de fundamentar e expor as razões de seu pensamento.

Nesse sentido é que o ensino está relacionado com a aquisição de certas competências que devem ser mobilizadas pelos estudantes. Como vimos nas definições trazidas até agora pelos professores, a sua finalidade é criar um contexto que propicie e valorize uma cultura de aprendizado baseada na sensibilização dos estudantes para a compreensão da natureza eminentemente social do seu processo de desenvolvimento. Espera-se que a Sociologia construa competências que mobilizem os saberes diversificados com as questões básicas encontradas no cotidiano dos estudantes, mas com a preocupação de romper com o senso comum e de alterar algumas de suas práticas sociais.

[...] Então, eu acho que num nível mais baixo da expectativa, um cidadão que sabe votar, por exemplo. Que tem condições de lidar com a realidade, percebendo ela, assim, se movimentar dentro dos locais com mais facilidade, por perceber cada instrumento que está sendo usado ali para orientar essa movimentação; isso num nível mais instrumental. $(F)$

Em vista dessa vontade, apontam que a disciplina tem que basear-se em três aspectos gerais: 1) as particularidades da Sociologia enquanto ciência; 2) o papel do seu 
ensino; e 3) as suas características que permitem a desnaturalização do mundo. É justamente a junção desses aspectos que dá forma a sua competência fundamental, que é fazer com que os estudantes sejam capazes de se utilizar das perspectivas sociológicas para produzir suas leituras e interpretações sobre a vida e assim tomar consciência sobre as questões sociais.

[...] tem que discutir a questão social o objetivo dela é exatamente esse, em outra situação eu posso até discutir cidadania, a construção de direito na sociedade moderna, mas eu tenho que fazer uma relação também com o que é ser cidadão na sociedade capitalista. (J)

[...] tem que se encontrar um ponto onde você não caia tanto no senso comum, não saia de dentro da proposta, mas você também entenda que eles têm um conhecimento que eles já trazem e tentar relacionar essas duas coisas. (E)

A tese que orienta esse postulado compreende que as particularidades dos conhecimentos sociológicos são capazes de oferecer uma estrutura cognitiva que possibilita ao estudante organizar os saberes e construir hipóteses sobre as causalidades e correlações de força dos acontecimentos sociais, determinando outro comportamento em relação às questões culturais e econômicas. Portanto, a noção de ensino que se extrai daí é construída em relação a essa competência e orientada para o estabelecimento de duas dimensões: 1) desenvolver uma inclinação intelectual; e 2) apresentar e envolver o estudante nas questões sociais. Tudo é elaborado para que essas dimensões façam sentido aos estudantes e os encaminhem para uma primeira reflexão.

As análises das concepções dos professores constituem fundamentos que nos permitem estruturar alguns aspectos relativos a duas categorias: o científico e o senso comum. Por isso, tomando suas percepções como referencial analítico entende-se que a noção de conhecimento escolar de Sociologia é constituída por uma proposta de ensino baseada numa abordagem que possibilite o acontecimento de processos de ruptura.

[...] com a possibilidade, também, de você desenvolver aquilo que você acha que os alunos estão necessitando, aquilo que você acha que é melhor aprofundar em um lado ou no outro. Eu vou preparando, vou modificando conforme as aulas que eu acho que eles precisam. Você parte da realidade do sujeito e vai construindo e reconstruindo. (I)

Isto é, o trabalho didático-pedagógico que envolve o ensino escolar de Sociologia 
busca considerar as rupturas que os estudantes precisam durante o processo de formação. Assim, depreende-se que a disciplina tem sido elaborada a partir dos métodos científicos e abordagens temáticas articuladas explicitamente com a cultura dos estudantes. A abordagem dos conceitos científicos é apresentada como o ponto de partida da estruturação da disciplina, entretanto ela transita por alguns outros fatores também. Isso significa, para estes professores, que o ensino escolar de Sociologia opera em dois níveis, na articulação dos temas com os conhecimentos científicos e no processo problematizador.

[...] Então assim eu costumo trabalhar os autores para começar e aí todos os temas que eu entro depois eu vou puxando. $(F)$

[...] Eu acho, por exemplo, eu tenho uma prática que já alguns anos eu adotei, que é passou esse primeiro momento de conhecimento do que é Sociologia, as ideias, os conceitos, a teoria desses clássicos é uma vez por mês trazendo temas de interesses deles. (B)

Então, o propósito da disciplina seria capacitar os estudantes para o emprego dos conhecimentos sociológicos, com a intenção de formá-los para que articulem a conceituação cientifica com as situações concretas. Depreende-se disso que, ao mesmo tempo, espera-se que ela funcione como emprego do aparato sociológico e como identificação das questões sociais. Trata-se do uso articulado da estrutura do conhecimento cientifico com as situações significativas recortadas pelos temas.

[...] acho que esses (os métodos científicos) deveriam vir sendo inseridos dentro do tema que você esteja trabalhando porque tornaria mais interessante. $(C)$

[...] Pro Ensino Médio você precisa trabalhar com temas, não tem como você atingir ou envolver os alunos sem um tema, sem trazer um tema. Eu entendo que tem que trabalhar com temas também e criar metodologias. (A)

É importante dizer que os temas são tratados como objetos de conhecimento, na medida em que sua compreensão representa a terminalidade do processo educativo. Os temas são selecionados e articulados com vistas a propor uma análise das contradições sociais, já que esse processo tornaria possível uma atuação na perspectiva de intervenção, mediante um processo que mescla ruptura e continuidade. Utilizam-se dos 
métodos científicos para transformar a interpretação que o estudante traz para a escola, direcionando-os para transformar as situações apresentadas pelos temas estudados.

\section{[...] que eles consigam relacionar cultura com a questão de etnocentrismo, com a questão de guerras históricas, com outras problemáticas. Indústria cultural, com questão de consumismo, capitalismo, daí com a questão da exploração do trabalho. $(F)$}

O ponto de partida é sempre o princípio explicativo do universo vivencial dos estudantes. Vale mencionar, que isso não é colocado pelos professores como aceitação da realidade, pelo contrário, trata-se de buscar a compreensão e a mudança na injunção desse universo com as ferramentas proporcionadas pela ciência. Segundo eles, o fundamental é evitar um conhecimento cuja orientação transforme o saber sociológico em um capital de conceitos separados de sua aplicação e utilização. Nesse sentido, é importante a articulação entre os temas relevantes para transformação da sociedade com os conhecimentos historicamente produzidos. A disposição dos temas e conteúdos dos programas e aulas está baseada nesse arquétipo do conhecimento, que envolve os momentos lógicos essenciais para a reflexão sobre a relação dialética entre ciência e natureza.

Os professores demonstram estarem preocupados com a organização e o planejamento de atividades produtoras de conhecimento que possibilite aos estudantes o entendimento tanto do produto quanto da dimensão processual desta produção. É fato importante que a sua exploração didática prime pela apresentação de temas ou conteúdos que tenham significância em relação às contradições sociais, pois, assim a apropriação dos conhecimentos científicos pelos estudantes fará o enfrentamento necessário a aquilo que Pierre Bourdieu (2011) denomina de "hierarquia dos atos científicos", ou seja, categoriza-se um processo de constatação - construção - ruptura dos objetos. O enfrentamento dessa realidade para superar o senso comum pode representar um ganho cultural por parte dos estudantes.

Verifica-se que a disciplina escolar de Sociologia tem se baseado num duplo recorte que varia de acordo com a interação entre as abordagens científicas e temáticas. Os conteúdos científicos são postos a prova nas tentativas de articulação entre conceitos, temas e teorias no estudo dos problemas reais. Nesse sentido valorizam-se mais os instrumentos construídos pelas variadas correntes de pensamento sociológico, 
dando ênfase no processo de produção de conhecimento e na contextualização dos princípios sociológicos. A tendência que observamos demonstra que esses recortes têm trabalhado com referências mútuas, no sentido de não se apresentarem separadamente, acompanhando de perto as propostas curriculares oficiais e os pressupostos axiológicos dos professores.

Nota-se uma mudança nesse aspecto ao considerarmos que em outro momento o ensino escolar de Sociologia fora caracterizado por opções teórico-metodológicas mais fechadas no que se refere a sua forma e conteúdo. Assim sendo, constata-se que a mediação da disciplina tem sido dimensionada pelas linhas mais gerais extraídas das propostas curriculares e as escolhas dos professores, entendendo-a como um "operador metodológico" com o objetivo de estreitar os vínculos entre os saberes da Sociologia e dos estudantes. Ao colocar a questão nestes termos os professores expressam suas preocupações em construir um tipo de conhecimento que combine os múltiplos estímulos presentes nos cotidianos dos estudantes com a linguagem da sociologia.

[...] é buscar dentro da disciplina, que é múltipla, o que vai ser significativo para aquele aluno. Não tem como ele entender categorias tão abstratas que a Sociologia trata, se você não particulariza isso no da realidade/cotidiano dele. (E)

Outro aspecto é que ele exponha as questões próprias da Sociologia e que provoque nos estudantes o interesse por esse campo de conhecimento. Esse esforço se materializa no processo de didatização, o que envolve metodologias específicas para tornar a linguagem clara e acessível para a compreensão dos temas, conceitos, teorias e autores. Para isso utilizam-se da reprodução de imagens, textos complementares, exercícios, entre outros recursos disponíveis para dar sentido ao ensino.

[...] dentro dessa proposta de fazer uma aula mais dinâmica, porque é uma matéria muito teórica, então você tem que criar elementos, levar um filme, levar o pessoal para uma atividade diferente, principalmente para os adolescentes. Você acaba incrementando sua proposta metodológica, com outros instrumentos. (A)

A tese central que podemos extrair das percepções dos professores acerca da disciplina e do ensino escolar de sociologia é que sua finalidade reside na possibilidade de se modificar os entendimentos sobre o mundo que vivemos e assim contribuir para 
alterar a maneira como estamos acostumados a enxergá-lo.

[...] Eu acho que é possível sim, apesar das limitações individuais de cada aluno e das limitações da escola, o valor dessa disciplina é lutar contra o senso comum, os meios de comunicação, os seus discursos. Os jovens estão muito preocupados com a sua questão aparente $e$ material, por isso, demonstrar questão do ser social propriamente. (H)

Isso fica bastante claro se considerarmos a recorrência dos termos "olhar sociológico" ou "imaginação sociológica". De fato, essa desnaturalização é colocada como papel referencial cuja mensagem é que a Sociologia pode ajudar a refletir sobre certas "verdades" construídas historicamente. Em outras palavras, o tipo de conhecimento oferecido pela disciplina é concebido com estranhamento daquilo que se mostra como mecânico e natural. Mas seu papel não se encerra por ai, espera-se que ele sirva como orientador do estudante diante dos problemas sociais e culturais recorrentes na modernidade. Não obstante, a preocupação dos professores em demonstrar que o conhecimento escolar de Sociologia trata de assuntos que fazem parte da vida cotidiana, mesmo que de forma distinta.

[...] Então, até eles começarem a perceber que não é uma disciplina que você pode só copiar o que está no quadro, demora, mas, desenvolve a imaginação sociológica, o raciocínio sociológico. Desenvolve sim. Apesar de escreverem muito errado, de terem dificuldade de internalizar os conceitos, mas você vai trabalhando. Aí eu pego um determinado texto e retomo com eles, Aí dou uma avaliação para ver o resultado disso. Porque senão não adianta, vai ficando vazio. (D)

Fica bastante clara a preocupação em se justificar um tipo de abordagem centrada em elementos que valorizem a sua importância social e científica. Quer dizer, observase que seu ensino e sentido aparecem relacionados com os aspectos mais científicos da disciplina (conceitos, metodologias e teorias), construindo e fundamentando uma relevância sociocultural em relação ao sistema de ensino escolar, ao passo, que revela uma tendência didático-pedagógica que demonstra como o processo de ensino e aprendizagem tem se estabelecido, ou seja, sua forma e conteúdo tratam do caráter da terminalidade do conhecimento e assim se relacionam com as questões sociais.

Assim, o trabalho de transposição didática se constrói em relação a duas 
dimensões: 1) formatar a disciplina em relação aos conceitos, teorias e temas; e 2) demonstrar a sua importância na formação dos estudantes enquanto mediação para as questões do cotidiano.

[...] dentro dos conteúdos específicos eu coloco as temáticas, então, a gente não deixa de trabalhar teoria/conteúdos porque a gente vai trabalhar com temas, a gente usa os temas, mas você está fazendo a relação conteúdo estruturante e conteúdo específico, nunca deixei de fazer essa relação, mesmo porque aqui mesmo na nossa formação a gente sempre foi cobrado eu acho isso muito importante, de a gente ser cobrado de mostrar a característica cientifica da Sociologia não ficar só trabalhando tema tirando do nada. $(G)$

Desta forma, o ensino e o sentido da disciplina passam por um processo de contextualização oferecido por seu conteúdo e forma, resignificando os conhecimentos científicos de maneira que o educando se identifique. A sua fundamentação está posta no ato de considerar as experiências sociais dos estudantes, relacionando o ensino com o contexto de ação social para que o conhecimento tenha validade.

[...] O conteúdo vai ser mais facilmente assimilado, porque é um conteúdo que tem a ver com o cotidiano dos alunos - e Sociologia se não tiver a ver com o cotidiano não vale de nada. $(E)$

A disciplina escolar de transita entre um tipo de preocupação mais sociológica e outra mais social. Isso pode parecer redundante, entretanto, as formas como os conhecimentos se assumem no sistema de ensino escolar mostram como os professores se esforçam em demonstrar uma unidade entre estas duas pontas. Nesse sentido é que a disciplina carrega um duplo papel, dando conta tanto de um ensino cujo sentido esteja vinculado aos aspectos científicos quanto de um ensino preocupado que sua forma e conteúdo não se distanciem das questões sociais, no sentido de demonstrar a sua aplicabilidade.

[...] A Sociologia não é mais disciplina somente para completar o Ensino Médio, ela tem que ser uma disciplina que contribua para o crescimento da pessoa. [...] É, fazer com que eles pensem, nossa Sociologia não é só aquilo que eu vi ou que ouvi dizer que é, não, a Sociologia é uma coisa que eu posso aplicar para minha vida. (B)

É interessante notar que essa correlação de forças tenha sua fundamentação na 
instabilidade gerada pela relação entre as propostas curriculares oficiais e ao projeto pedagógico de cada professor. Quer dizer, de um lado temos as propostas que carregam os objetivos gerais para a disciplina e do outro a interpretação própria das ciências sociais sobre a noção de conhecimento.

\section{Considerações finais}

No contexto específico pesquisado foi possível perceber que a produção da disciplina escolar de Sociologia é bastante particular, pois sua centralidade é construída a partir da transitoriedade entre três categorias que se relacionam reciprocamente: ciência, cidadania e crítica social. As percepções dos professores demonstram que o ensino escolar de Sociologia fundamenta-se no entrecruzamento dessas categoriais, que foram sendo construídas historicamente pelas propostas curriculares e pelos desenvolvimentos teóricos oriundos das Ciências Sociais e que, sujeitadas aos processos de transposição didático-pedagógicos, acabaram relativizadas e ressignificadas.

Por isso, pode-se dizer que para estes professores o ensino escolar de Sociologia esta sendo pensado em relação a dois aspectos fundamentais: os temas e objetivos gerais para a educação definidos pela última reforma educacional (cidadania e trabalho) e as definições sobre a disciplina construídas pelas ciências sociais (conceitos, metodologias e teorias). A disciplina esta diretamente influenciada por essa dicotomia, pois, basta perceber que na prática sua construção apresenta um movimento de transitoriedade entre noções de ambas as partes. Isso é importante à medida que explica alguns dos debates e que demonstram preocupações diferentes se considerarmos as outras disciplinas.

E, considerando todos esses aspectos, podemos afirmar que, de modo geral, o processo de legitimação da disciplina escolar de Sociologia em andamento faz com que a produção dos discursos sobre seu ensino alcance importantes níveis de elaboração. Historicamente, mesmo diante da complexidade institucional confrontada e das exigências impostas à disciplina pela conjuntura, sempre houve certa centralidade diante de alguns temas dentro do debate sobre os contornos disciplinares e os objetos do ensino. Isso sinalizava um ponto comum em todos os espaços que permeavam o contexto de produção da disciplina, que era a intenção predominante de oferecê-la da 
maneira mais apropriada, dando mais atenção a como e $o$ quê da Sociologia poderia ser ensinado e aprendido na educação escolar.

\section{Referências}

BOURDIEU, Pierre. A economia das trocas simbólicas. Introdução, organização e seleção Sérgio Micelli. 7. ed. São Paulo: Perspectiva, 2011.

BRASIL. Ministério da Educação. Secretaria de Educação Básica. Orientações curriculares para o ensino médio. Brasília, DF: MEC, 2004.

CHERVEL, André; COMPÉRE, Marie-Madeleine. As humanidades no ensino. In: Educação e Pesquisa. Vol. 25, n. 2, São Paulo, Julho/Dezembro, 1999.

FOUCAULT, Michel. A ordem do discurso. Aula inaugural no College de France, pronunciada em 2 de dezembro de 1970. Tradução de Laura Graga de Almeida Sampaio. $5^{\text {a }}$ edição. São Paulo: Loyola, 1999.

FORQUIN, Jean-Claude. Escola e cultura: as bases sociais e epistemológicas do conhecimento escolar. Tradução de Guacira Lopes Louro. Porto Alegre: Artes Médicas, 1992.

GOODSON, Ivor F. Currículo: Teoria e História. Tradução de Attílio Brunetta. Apresentação de Tomaz Tadeu da Silva. Petrópolis, RJ: Vozes, 1995.

GOODSON, Ivor F; MARSH, Colin J. Studying school subjects: A guide. London: Falmer Press, 1996.

GOODSON, Ivor. F. O currículo em mudança: Estudos na construção social do currículo. Coleção Currículo, Políticas e Práticas. Porto: Porto Editora, 1997.

JULIÁ, Dominique. Disciplinas escolares: objetivos, ensino e apropriação. In: LOPES, Alice Casemiro; MACEDO, Elizabeth (org.). Disciplinas e integração curricular: história e políticas. Rio de Janeiro: DP\&A, 2002, pg. 37 - 71.

NEUHOLD, Roberta. Sociologia do ensino de Sociologia: os debates acadêmicos sobre a constituição de uma disciplina escolar. 2014. 334 f. Tese (Doutorado) - Faculdade de Educação, Universidade de São Paulo, São Paulo, 2014.

VINÃO FRAGO, Antônio. A história das disciplinas escolares. In: Revista brasileira de história da educação. N. 18, set/dez. 2008.

VINÃO FRAGO, Antônio. Sistemas educativos, culturas escolares e reformas. Coleção 
Política, Media e Estudos culturais. Mangualde: Edições Pedagogo, 2007.

YOUNG, Michael F. D. (ed.). Knowledge and control: new directions for the sociology of education. London: Collier Macmillan, 1971.

Recebido em 15 de agosto de 2015.

Aprovado em 06 de setembro de 2016. 